\title{
TRADUÇÃO AUDIOVISUAL ACESSÍVEL (TAVA): AUDIODESCRIÇÃO, JANELA DE LIBRAS E LEGENDAGEM PARA SURDOS E ENSURDECIDOS
}

\author{
ACCESSIBLE AUDIOVISUAL TRANSLATION: \\ AUDIODESCRIPTION, SIGN LANGUAGE WINDOW AND \\ SUBTITLING FOR THE DEAF AND THE HARD-OF-HEARING
}

\section{Vera Lúcia Santiago Araújo* Soraya Ferreira Alves ${ }^{* *}$}

Em março de 2017 o museu Ara Pacis, em Roma, lançou um projeto inovador combinando arte e tecnologia: uma visita que propicia aos visitantes surdos, ensurdecidos e deficientes visuais uma experiência multissensorial. Cada visitante recebe um "companheiro de viagem" - como são chamados os aparelhos que proveem a todos, no percurso da visita e passagem pelas obras, audiodescrições, adaptações visuais, diálogos, comentários, e até mesmo modelizações das obras

* Vera Lúcia Santiago Araújo: Professora Adjunta da Universidade Estadual do Ceará - UECE e pesquisadora nível 2 do CNPq. Tem experiência na área de Linguística Aplicada, com ênfase em Tradução, atuando principalmente nos seguintes temas: tradução audiovisual, legendaçãolegendagem, audiodescrição e tradução audiovisual e ensino. Participou como uma das elaboradoras do Guia de Produção Audiovisual Acessível, para a Secretaria do Audiovisual do Ministério da Cultura (SAv/MinC), que serve como material de referência para realizadores do audiovisual no Brasil.vera.santiago@uece.br

** Soraya Ferreira Alves: Professora Ajunta da Universidade de Brasília - UnB, vinculada ao Departamento de Línguas Estrangeiras e Tradução, ao Curso de Tradução e ao Programa de Pósgraduação em Estudos da Tradução, onde atua principalmente nos seguintes temas: tradução literária e audiovisual. Tem trabalhos publicados nas áreas de crítica literária, tradução intersemiótica e audiovisual. Coordena grupo de pesquisa em Tradução Audiovisual, com foco em audiodescrição para pessoas com deficiência visual. É audiodescritora. so.ferreira@uol.com.br 
em 3D. Esse museu em Roma é apenas um entre outros que, em diversos países ${ }^{1}$, vêm implementando projetos que garantem a acessibilidade às paisagens culturais e, portanto, a participação de todos na vida das comunidades.

O tema da acessibilidade também vem ganhando cada vez mais espaço no Brasil $^{2}$. A Constituição de 1988 traz uma legislação sobre deficiência ainda esparsa, sendo o Decreto da Acessibilidade, que regulamenta as leis que asseguram os direitos das pessoas com deficiência, de 2004. Há alguns anos um marco legal sobre leis e direitos vem sendo construído e aprimorado.

Esta publicação temática vem contribuir para uma reflexão sobre o tema, mais especificamente sobre a acessibilidade comunicacional, que exige três modalidades de tradução audiovisual acessível, a saber, a audiodescrição, a legendagem para surdos e ensurdecidos e a janela de interpretação em Libras.

Com relação à acessibilidade comunicacional, a Convenção sobre Direitos das Pessoas com Deficiência (CDPD) define "Comunicação" como abrangendo

....as línguas, a visualização de textos, o Braille, a comunicação tátil, os caracteres ampliados, os dispositivos de multimídia acessível, assim como a linguagem simples, escrita e oral, os sistemas auditivos e os meios de voz digitalizada e os modos, meios e formatos aumentativos e alternativos de comunicação, inclusive a tecnologia da informação e comunicação acessíveis. (CDPD, 2008, p. 24)

A Convenção, ratificada pelo Brasil em 2008, com equivalência de emenda constitucional junto a seu Protocolo Facultativo, foi um grande marco para as práticas de acessibilidade.

Mais recentemente, a Lei Brasileira de Inclusão, LEI No 13.146 de 6 de julho de 2015 (em vigor a partir de 02 de janeiro de 2016), promove a inserção de grupos de pessoas com deficiência, sendo de aplicação obrigatória. Alguns de seus artigos, elencados abaixo, tratam especificamente da acessibilidade audiovisual:

Art. 42. A pessoa com deficiência tem direito à cultura, ao esporte, ao turismo e ao lazer em igualdade de oportunidades com as demais pessoas, sendo-lhe garantido o acesso:

I - a bens culturais em formato acessível;

II - a programas de televisão, cinema, teatro e outras atividades culturais e desportivas em formato acessível; e

III - a monumentos e locais de importância cultural e a espaços que ofereçam serviços ou eventos culturais e esportivos.

\footnotetext{
1 Sobre espaços culturais com projetos de acessibilidade ver $<$ http://fr.arapacis.it/didattica/progetti speciali/visita_guidata_tattile_sensoriale_con_operatori_specializzati_21_11> e < http:// fr.museiincomune roma.it/didattica/progetti_speciali/musei_da_toccare_visite_tattili $>$

2Acessibilidade no Brasil - disponível em ${ }^{-}<$http://www.portalacesse.com/2017/07/08/espacosculturais-sao-referencias-em-acessibilidade/ $>$ 
§ $1^{\text {óE }}$ vedada a recusa de oferta de obra intelectual em formato acessível à pessoa com deficiência, sob qualquer argumento, inclusive sob a alegação de proteção dos direitos de propriedade intelectual.

Art. 67. Os serviços de radiodifusão de sons e imagens devem permitir o uso dos seguintes recursos, entre outros:

I - subtitulação por meio de legenda oculta;

II - janela com intérprete da Libras;

III - audiodescrição.

Em setembro de 2016, a Ancine lança uma Instrução Normativa ${ }^{3}$, com relação às salas de exibição comercial, os artigos $3^{\circ}$ e $4^{\circ}$ determinam que cabe ao exibidor/ às salas de exibição "dispor de tecnologia assistiva voltada à fruição dos recursos de legendagem, legendagem descritiva ${ }^{4}$, audiodescrição e LIBRAS - Língua Brasileira de Sinais", com a observação de que tais recursos não interfiram na "na fruição dos demais espectadores". Os artigos $6^{\circ}$ e $7^{\circ}$ estabelecem prazos gradativos para a adequação à nova regra, que variam de acordo com o número de salas de cinema de cada grupo exibidor. Em 14 meses, cerca de 50\% do parque exibidor terá que contar com os recursos implantados de legendagem descritiva, audiodescrição e libras. Em 2 anos todo o parque exibidor deverá contar com os recursos de legendagem descritiva, audiodescrição e libras.

Dessa forma, a implementação dos recursos de acessibilidade audiovisual, além de uma prática prevista por lei, devem primar pela qualidade, para poderem atender seus usuários de maneira a que possam usufruir das mais diversas manifestações sociais. Para esse atendimento com qualidade, o profissional deve ter formação e treinamento adequados.

Segundo Jorge Díaz-Cintas (2007), a figura desse profissional tradutor precisa englobar diversas habilidades e é chamado pelo autor de «acessibilitador»:

Falamos de "acessibilidade", mas carecemos de um conceito geral que aglutine os responsáveis encarregados da mesma, contrariamente ao que acontece no terreno da tradução (tradutor) e da interpretação (intérprete). Dado o impulso atual desta nova atividade social e profissional e suas boas perspectivas de futuro, talvez seja o momento adequado de cunhar um novo termo e começar a falar da figura do "acessibilitador", como especialista último no terreno da acessibilidade (DÍAZ-CINTAS, 2007, p. 46).

Ao abordarem as exigências do profissional da audiodescrição, Alves e Teixeira (2015) esclarecem a importância do conhecimento e da formação desse

3 Disponível em: < http://www.ancine.gov.br/sala-imprensa/noticias/ancine-regulamenta-inclus-ode-recursos-de-acessibilidade-auditiva-e-visual $>$

4 Obs. Aquilo que o governo chama de legendagem descritiva, os teóricos da legendagem denominam de legendagem para surdos e ensurdecidos (LSE). O termo é tradução do inglês subtitling for the deaf and the bardof-hearing $(\mathrm{SDH})$. 
profissional. Sua fala, porém, pode ser estendida a todo e qualquer profissional tradutor de produtos audiovisuais:

[...] faz-se necessário ao processo de tradução advindo da audiodescrição e àqueles que com ela trabalham o entendimento da confecção do produto imagético, o filme, e sua gramática. Questões relativas à construção da imagem, som, iluminação, pontos-de- vista, campo e contracampo, enquadramento e planos, são essenciais ao audiodescritor nesse processo de tradução tão delicado. (ALVES e TEIXEIRA, 2015, p. 172)

Para os autores, o que determina as escolhas do profissional da audiodescrição é não só a necessidade de pôr em contato o produto e o espectador com deficiência visual, mas também proporcionar um "acesso irrestrito à informação visual" levando em conta que caberá ao espectador construir inferências tirar suas próprias conclusões. O trabalho de qualidade do audiodescritor exige, portanto, levar em conta:

Questões que compõem a narrativa fílmica, como o tempo e o espaço, devem ser consideradas e profundamente entendidas, pois são essenciais ao desenvolvimento da trama fílmica e podem ser de suma importância no desfecho de cenas de suspense e tensão. Nesse sentido, compreender a narrativa fílmica e seu desenvolvimento polissêmico pode esclarecer e justificar determinadas escolhas feitas na audiodescrição. (ALVES e TEIXEIRA, 2015, p. 172)

Algumas publicações no país já abordaram a Tradução Audiovisual (TAV) e suas modalidades (legendagem, dublagem, voice-over e audiodescrição), assim como a interface com a tradução e a interpretação em Língua de Sinais (TILS). No entanto, esta é a primeira publicação no país que discute a TAV voltada para a pesquisa em acessibilidade aos meios audiovisuais de pessoas com deficiência sensorial, sob a denominação de Tradução Audiovisual Acessível (TAVa). Dentre as coletâneas que abordaram a TAV anteriormente, podemos citar o dossiê de TAV (2005) no periódico Cadernos de Tradução da UFSC, o número especial do periódico TradTerm da USP (2007), os livros organizados por Motta e Romeu (2010), Araújo e Aderaldo (2013), Tavares (2013), Vilela, Martins e Leite (2015), Naves, Mauch, Alves e Araújo (2016), Aderaldo, Mascarenhas, Alves, Araújo e Dantas (2016), Carpes (2016) e Mayer e Pinto (2017).

O dossiê da Cadernos de Tradução (2005) trouxe oito artigos de oito pesquisadores do Brasil e da Europa, trabalhando com pesquisas sobre dublagem, adaptação fílmica e localização de software, os quais naquela data ainda eram considerados parte da TAV. Nenhum deles tratou da questão da acessibilidade, embora mereça destaque o número especial da TradTerm (2007), o qual trouxe nove artigos sobre TAV (3 sobre legendagem de dois sobre dublagem), além de quatro artigos sobre TAVa, um sobre legendagem para surdos e ensurdecidos (LSE) e três 
sobre audiodescrição (AD). Os artigos sobre TAVa versavam, principalmente, sobre experiências com LSE e AD na Espanha, em Portugal e no Brasil.

As publicações restantes, com exceção de Vilela, Martins e Leite, e também Naves, Mauch, Alves e Araújo (2016), tratam somente da audiodescrição. Em Motta e Romeu (2010), foram apresentados 28 artigos sobre as experiências nas várias modalidades de audiodescrição (14 artigos), o depoimento de pessoas com deficiência visual (PcDV) sobre o recurso (9 artigos) e os agentes culturais que ofereciam seus produtos com AD na época ( 5 artigos). Como se pode perceber, a maioria dos trabalhos versava sobre questões profissionais, mercadológicas e sociais, embora dois deles já tangenciassem a acessibilidade como tema de pesquisa. Em 2017, saiu mais uma coletânea, contendo artigos, envolvendo os pressupostos teóricos (4 artigos), a práxis (4 artigos) e as interfaces ( 5 artigos) para a pesquisa em AD.

Foi somente em 2013 que tivemos a primeira publicação dedicada totalmente à pesquisa em AD. O livro organizado por Araújo e Aderaldo (2013) contém 13 capítulos de pesquisadores brasileiros dedicados a estudos enfocando as diferentes modalidades de $\mathrm{AD}$ (cinema, teatro, obra de arte), múltiplas interfaces com os Estudos da Tradução (Fonética, Fonologia, Fonoaudiologia, Sistemas de Avaliatividade e Comunicação Social) e vários construtos teóricos metodológicos, com ênfase em pesquisas exploratórias, as quais visavam avaliar a recepção de PcDVs a produtos audiodescritos. Outra coletânea publicada no mesmo ano foi a de Tavares (2013). Todos os oito artigos são dedicados à apresentação da $\mathrm{AD}$ para produtores culturais.

O ano de 2016 trouxe duas coletâneas, enfocando a pesquisa em audiodescrição. A primeira é a de Aderaldo, Mascarenhas, Alves, Araújo e Dantas (2016), e nelas estão publicados 11 artigos sobre reflexões a respeito de questões mais pontuais sobre a $\mathrm{AD}$ como a questão da neutralidade na interpretação, as particularidades da locução, a priorização da informação, a narratologia fílmica e a consultoria fornecida pelas PcDVs. A segunda é a de Carpes (2016), a qual é composta de 9 artigos de pesquisadores e profissionais de vários recantos do país, versando sobre a (não) neutralidade, a consultoria, o uso na educação de PcDVs e experiências com AD de cinema, teatro e jornalismo.

Dois livros abordaram especificamente as três modalidades de TAVa (VILELA, MARTINS e LEITE (2015); NAVES, MAUCH, ALVES e ARAÚJO (2016). Vilela, Martins e Leite (2015) apresentam oito artigos de pesquisadores que se debruçam sobre o uso dessas modalidades para promover a acessibilidade no ensino superior. Finalmente, temos Naves, Mauch, Alves e Araújo (2016). As autoras, juntamente com outros pesquisadores da área de $\mathrm{TAVa}$, elaboraram um guia com diretrizes para a elaboração de $\mathrm{AD}$, LSE e Janela de Libras, para que cineastas e produtores e 
distribuidores cinematográficos tornem suas produções acessíveis. De acordo com a instrução normativa 132 de 15 de março de 2017:

Todos os projetos de produção audiovisual financiados com recursos públicos federais geridos pela ANCINE deverão contemplar nos seus orçamentos serviços de legendagem, legendagem descritiva, audiodescrição e LIBRAS - Língua Brasileira de Sinais.

O guia tem o objetivo de orientar os profissionais da área a produzir material acessível de qualidade para ser exibido para o público com deficiência. Os segmentos de distribuição e exibição de produtos cinematográficos também estão regulamentados quanto a este quesito, segundo a instrução normativa 128 de 13 de setembro de 2016.

O guia define assim as três modalidades de TAVa:

\section{Audiodescrição}

A audiodescrição é uma modalidade de tradução audiovisual, de natureza intersemiótica, que visa tornar uma produção audiovisual acessível às pessoas com deficiência visual. Trata-se de uma locução adicional roteirizada que descreve as ações, a linguagem corporal, os estados emocionais, a ambientação, os figurinos e a caracterização dos personagens.

\section{Janela de Interpretação de Língua de Sinais}

É o espaço destinado à tradução entre uma língua de sinais e outra língua oral ou entre duas línguas de sinais, feita por Tradutor e Intérprete de Língua de Sinais (TILS), na qual o conteúdo de uma produção audiovisual é traduzido num quadro reservado, preferencialmente, no canto inferior esquerdo da tela, exibido simultaneamente à programação.

\section{Legendagem para surdos e ensurdecidos (LSE)}

É a tradução das falas de uma produção audiovisual em forma de texto escrito, podendo ocorrer entre duas línguas orais, entre uma língua oral e outra de sinais ou dentro da mesma língua. Por ser voltada, prioritariamente, ao público Surdo e Ensurdecido, a identificação de personagens e efeitos sonoros deve ser feita sempre que necessário. (NAVES, MAUCH, ALVES e ARAÚJO, 2016, pp. 15-16)

O termo Tradução Audiovisual Acessível foi proposto por Jimenez Hurtado (2007; JIMENEZ HURTADO; RODRÍGUEZ; SEIBEL, 2010). Para a autora, a TAVa, além de englobar estudos sobre as diferentes práticas tradutórias usadas 
para traduzir conteúdos intra e interlinguísticos caracterizados pela intersemiose entre som e imagem, também está bem mais centrada em aspectos relacionados ao espectador (2007).

A interface texto-imagem, a relação entre informação verbal e não verbal, assim como as implicações destes tipos de informação para a tradução acessível e a acessibilidade universal aos meios de comunicação formam parte da busca por novas metodologias de estudo da textualidade multimodal. (JIMENEZ HURTADO; RODRÍGUEZ; SEIBEL, 2010, p.19)

O termo vem sendo usado em várias pesquisas em TAV e acessibilidade na UECE, desde Aderaldo (2014). Apesar de parecer redundante, já que toda tradução é, por definição, uma forma de tornar acessíveis os mais diversos tipos de produção (artística, técnica, e outras), pensamos que a expressão "tradução acessível" já se consolidou na área, como podemos perceber pelas contribuições recebidas para este número da revista Trabalhos em Linguística Aplicada. Pudemos perceber que a TAVa está se fortalecendo e se tornando uma subárea bastante produtiva, e é mostra disso que este Dossiê conta com onze artigos de universidades de quatro regiões do Brasil: Nordeste (Universidade Estadual do Ceará, Universidade Federal do Ceará e Universidade de Fortaleza - UNIFOR), Sudeste (Universidade de São Paulo, Universidade de Campinas, Universidade Estadual Paulista, Universidade Federal de São Carlos e Universidade Metodista de Piracicaba), Sul (Universidade de Caxias do Sul, Allya Language Solutions e Faculdade Murialdo, ambas de Caxias do Sul) e Centro-Oeste (Universidade de Brasília e Secretaria de Estado de Educação do Distrito Federal, SEEDF).

Os temas dos artigos enfocam as principais modalidades de TAVa (audiodescrição (AD), janela de Libras e legendagem para surdos e ensurdecidos (LSE)), além de um trabalho que trata do mapeamento da subárea. Esse é justamente o texto que abre o volume. Samira Spolidorio descreve a Plataforma de Acessibilidade Midiática (MAP) que tem como meta "centralizar as informações sobre acessibilidade audiovisual [...] sobre legislação, pesquisas, treinamentos, e notícias em geral sobre questões ligadas às diversas modalidades de acessibilidade" em diversos países. A autora mapeia o estado da arte no Brasil com o objetivo de inserir as informações sobre nossa produção na plataforma.

\section{ACESSIBILIDADE E AUDIODESCRIÇÃO}

A audiodescrição é tema de cinco artigos deste dossiê. No primeiro, Lucinéa Marcelino Villela trata do erotismo em roteiros de audiodescrição de filmes, comentando cenas do filme brasileiro Praia do Futuro, e defende que o espectador 
com deficiência visual deve ter, com o recurso de acessibilidade, a possibilidade de alcançar as mesmas sensações que o vidente ao assistir a cenas que podem provocar envolvimentos ambivalentes como brutalidade mesclada a prazer, sensualidade e, sobretudo, emoções. Para a autora, o trabalho com esse tipo de cena revela-se um forte argumento para a consideração de qualquer forma de tradução como processo autoral e um desafio à norma da "objetividade" do audiodescritor.

Em seguida, Wilson Júnior de Araújo Carvalho, Bruna Alves Leão e Charleston Teixeira Palmeira apresentam três estudos sobre locução na audiodescrição. Com base em suas análises e em seus resultados, defendem a necessidade de a audiodescrição ter seu roteiro planejado, mas também ser mais bem trabalhada no que se refere, principalmente, ao uso da ênfase, da curva melódica e do ritmo. Esses estudos pretendem contribuir para o aperfeiçoamento da locução da audiodescrição para cinema e teatro, tendo em seu horizonte a transmissão das nuances e emoções da obra.

Em Avaliar ou não avaliar, eis a questão: o estado da arte nas pesquisas sobre avaliatividade em audiodescrição, Pedro Henrique Lima Praxedes Filho e Daniel de Albuquerque e Arraes relatam o percurso investigativo das pesquisas que verificam a viabilidade teórica e prática de o audiodescritor produzir roteiros neutros, ancorando-se principalmente no arcabouço teórico-metodológico da Linguística Sistêmico-Funcional e, dentro desta, no Sistema de Avaliatividade. Os resultados apontam para a natureza eminentemente multimodal do roteiro de $\mathrm{AD}$, bem como para sua flagrante integração semiótica com o objeto audiodescrito, além de sugerir a necessidade de pesquisas com novos desenhos metodológicos que levem em consideração essa natureza.

Já Soraya Ferreira Alves e Veryanne Couto Teles apresentam uma proposta de modelo de pré-roteiro para audiodescrição simultânea embasada em aspectos teóricos, bem como na própria prática das autoras como audiodescritoras em Brasília. Na perspectiva de sistematizar uma metodologia para auxiliar essa prática, foram elaboradas sugestões que podem ser adotadas na audiodescrição simultânea de eventos ao vivo, a fim de contribuir na formação de audiodescritores no Brasil.

O último artigo sobre a modalidade de audiodescrição, de autoria de Milena Schneid Eich, Lisiane Ott Schulz e Luciana Santos Pinheiro, reflete sobre a importância da audiodescrição das imagens nos livros didáticos de língua inglesa na atualidade para que pessoas com deficiência visual realizem, de forma autônoma, as atividades que necessitam de observação, compreensão e/ ou interpretação dessas imagens para sua resolução. Suas considerações estão pautadas em exemplos de atividades e nas análises destas. 


\section{ACESSIBILIDADE: LIBRAS E LEGENDAGEM PARA SURDOS E ENSURDECIDOS (LSE)}

Os cinco artigos sobre LIBRAS e LSE tratam principalmente de estudos teórico-metodológicos envolvendo a Linguística de Corpus e Estudos Experimentais. Em Janelas de libras e gêneros do discurso: apontamentos para a formação e atuação de tradutores de lingua de sinais, Vinicius Nascimento faz uma reflexão sobre as questões enunciativodiscursivas, considerando a relação dialética e dialógica entre o vídeo como um todo e a Janela de Libras, normalmente avaliada somente por questões técnicas, tais como tamanho, recorte e posição.

Patrícia Araújo Vieira, Elisângela Nogueira Teixeira e Élida Gama Chaves analisam a recepção de espectadores surdos e ouvintes a documentários legendados por meio de um estudo exploratório-experimental com rastreador ocular. O parâmetro analisado foi o da segmentação, ou divisão, de fala em legendas. Os resultados são surpreendentes e apontam que as legendas de velocidade alta, desde que sejam segmentadas segundo os padrões preconizados por pesquisadores da área, são as mais eficazes na recepção do gênero em questão.

Trabalho semelhante foi realizado por Silvia Malena Modesto Monteiro e João Francisco Dantas, tendo somente o corpus como diferença. Em Tradução audiovisual acessivel (TAVa): a segmentação linguística na Legendagem para Surdos e Ensurdecidos (LSE) da campanba política na televisão em Fortaleza, os autores investigaram a legendagem das campanhas eleitorais exibidas nos canais de televisão brasileiros. Os resultados sugeriram que as legendas de uma linha, características desse tipo de produção legendada e fora dos parâmetros do que seria uma legenda bem segmentada, traziam dificuldades de recepção para os participantes.

Ana Katarinna Pessoa do Nascimento, por meio de um estudo baseado em corpus, procura encontrar sintagmas e orações convencionais que melhor traduzam sons na legendagem de filmes. Os resultados preliminares da análise de 15 filmes mostram que o melhor caminho seria "privilegiar sons que interajam com os personagens em tela e dar preferência à tradução por meio de orações que possuam uma ideia completa, de modo que se saiba qual a origem e o tipo de ruído que se está traduzindo".

Encerrando o Dossiê, temos o artigo de Vera Lúcia Santiago Araújo, Italo Alves Pinto de Assis e Daniel de Albuquerque e Arraes, o qual avalia a segmentação linguística da legendagem em novelas também por meio de uma metodologia baseada em corpus. Os autores demonstram que há uma quantidade significativa de problemas de segmentação, principalmente no que diz respeito aos sintagmas verbal e nominal, respectivamente. 


\section{REFERÊNCIAS BIBLIOGRÁFICAS}

ADERALDO, M.F.; DANTAS, J.F.; MASCARENHAS, R.; ARAÚJO, V.L.S. Pesquisas teóricas eaplicadas em audiodescrição. Natal: EDUFRN, 2016, 212 p. Disponível em https:// repositorio.ufrn.br/jspui/handle/123456789/22612. Acesso em 26/05/2017.

ALVES, S. F.; TEIXEIRA, C. R. Audiodescrição para pessoas com deficiência visual: princípios sociais, técnicos e estéticos. In SANTOS; Cynthia; BESSA, Cristiane $\mathrm{R}_{i}$ LAMBERTI, Flávia (org). Tradução em Contextos Especializados. Brasília: Editora Verdana, 2015.

ARAÚJO, V.L.S; FRANCO, E.P.C. (org.) Dossiê de Tradução Audiovisual. Cadernos de Tradução. Número 16, Volume 2, 2005, 152p. Disponível em https://periodicos. ufsc.br/index.php/traducao/issue/view/439. Acesso em 14/11/2017.

ARAÚJO, V.L.S; FRANCO, E.P.C. (org.) TRADTERM, número 13, 2007, 288p. http:// www.revistas.usp.br/tradterm/article/view/47470/51198. Acessado em 30/05/2017.

ARAÚJO, V.L.S.; ADERALDO, M.F. (Ed.) Os novos rumos da pesquisa em audiodescrição no Brasil. Curitiba: CRV, 2013, 218p.

CARPES, D. S. Audiodescrição: práticas e reflexões. Santa Cruz do Sul, Rio Grande do Sul: Catarse, 2016, 165p. Disponível em http://editoracatarse.com.br/site/wpcontent/uploads/2016/02/Audiodescri\%C3\%A7\%C3\%A3o-pr\%C3\%A1 ticas-ereflex\%C3\%B5es.pdf. Acesso em 14/11/2017.

CONVENÇÃO SOBRE DIREITOS DAS PESSOAS COM DEFICIÊNCIA (CCPD). Presidência da República Secretaria de Direitos Humanos. Secretaria Nacional de Promoção dos Direitos da Pessoa com Deficiência. 4a edição revista e atualizada, 2011. Disponível em: http://www.pessoacomdeficiencia.gov.br/ app/publicacoes/ convencao-sobre-os-direitos-das-pessoas-com-deficiencia

DÍAZ CINTAS, J. Por una preparación de calidad en accesibilidad audiovisual. In: TRANS, N. ${ }^{\circ}$ II. London: Roehampton University, 2007, p. 45-59.

JIMENEZ-HURTADO, C. Traducción y accessibilidad: subtitulación para sordos y nuevas modalidades de traducción audiovisual. Frankfurt: Peter Lang, 2007, 287p.

JIMENEZ-HURTADO, C.; RODRÍGUEZ, A.; SEIBEL, C. Um corpus de cine Teoría y práctica de la audiodescripción. Granada: Ediciones Tragacanto, 2010, 333p. 
Lei Basileira de Inclusão, LEI No 13.146 de 6 de julho de 2015. Disponível em http:// www.planalto.gov.br/ccivil_03/_ato2015-2018/2015/lei/113146.htm

NAVES, S. B; MAUCH, C; ALVES, S. F; ARAÚJO, V. L. S. Guia para Produçẽes Audiovisuais Acessíveis. Brasília: Ministério da Cultura/Secretaria do Audiovisual, 2016, 85p. Disponível em https://grupoleaduece.blogspot.com/p/guia-para-producoesaudiovisuais.html. Acesso em 30/05/2017.

MAYER, F.; PINTO, J. Perspectivas contemporâneas em audiodescrição. Belo Horizonte: PUC Minas, Programa de Pós-Graduação em Comunicação, 2017, 165 p. Disponível em www.fca.pucminas.br/wp.../Perspectivas-Contemporaneas-e-m-AudiodescriçãoFinal.pdf Acesso em 14/11/2017.

MOTTA, L.M.M.; ROMEU FILHO, P. (Ed) Audiodescrição. Transformando imagens em palavras. São Paulo: Secretaria de Estado dos Direitos da Pessoa com Deficiência, 2010, 250p. Disponível em http://pessoacomdeficiencia.sp.gov.br/usr/share/documents/ LIVRO_AUDIODESCRICAO_TRANSFORMANDO_IMAGENS_EM_ PALAVRAS.pdf. Acesso em 19/06/2017.

TAVARES, L. B. Notas proemias: acessibilidade comunicacional para produções culturais. Recife: Editora do Organizador, 2012. 112 p.

VILELLA, L. M.; MARTINS, E. S. E. O, LEITE, L. P. Recursos de acessibilidade aplicados ao ensino superior. Bauru: FC/UNESP, 2015, 107p. 